\title{
Women's perception of safety and utilization of herbal remedies during pregnancy in a local government area in Nigeria
}

\author{
A. E. Olowokere, O. Olajide \\ Department of Nursing Science, Obafemi Awolowo University, Ile-Ife, Nigeria
}

Correspondence: A. E. Olowokere. Address: Department of Nursing Science, Obafemi Awolowo University, Ile-Ife, Nigeria. Email: ayaolowo@yahoo.com

Received: April 24, 2013

Accepted: July 14, 2013

Online Published: August 22, 2013

DOI : $10.5430 / \mathrm{cns} . v 1 \mathrm{n} 4 \mathrm{p9}$

URL: http://dx.doi.org/10.5430/cns.v1n4p9

\begin{abstract}
This descriptive study examined the perception of safety and utilization of herbal remedies during pregnancy using a convenience sampling of 300 women. The women who participated in the study were selected at household level from rural communities in Ife-North local government area of Osun state in Nigeria. Data was collected with the aid of semi-structured questionnaire using interviewer-administered method after informed consent had been taken from each participant. The results show that the women had positive perception about the safety and efficacy of herbs over conventional drugs in pregnancy. Greater percentage of the participants studied had used herbs at one point or the other during pregnancy. Local concoction also referred to as "Agbo" was the most used herbs by the women. The need for laboratory exploration of these herbs was emphasized by this study because of the high usage by pregnant women without any empirical evidence on its safety and efficacy.
\end{abstract}

\section{Key words}

Herbal remedies, Pregnant women, Perception, Safety, Nigeria

\section{Background}

Herbs have been used as a form of alternative therapy over the years and their use as potent sources of remedies have become an integral part of indigenous cultures across the world. While orthodox medicine has evolved over time to be the most preferred and promoted means of health care, the concurrent use of herbal remedies has not been abandoned entirely across the globe. The use of herbal herbal remedies still persists in local communities, most especially in developing countries where access to orthodox medicine may be unavailable or unaffordable. Herbs in this study involve the use of plant products in their raw or cooked forms which have not been subjected to laboratory investigations for their safety and efficacy.

Bearing in mind the peculiar challenges experience by women during pregnancy, there is higher possibility of increased intake of herbal remedy as a form of alternative care among women in the local communities. These remedies are used by women to relieve minor symptoms of pregnancy such as nausea, vomiting, and low back pain, and also to prepare for labour or other unrelated health issues such as colds and respiratory illnesses or skin problems ${ }^{[1]}$. Herbal remedy may also 
be used to protect the fetus from evil in-vitro and to have a healthy child ${ }^{[2,3]}$. However, the use of herbal remedies may differ from women to women depending on their perception of their efficacy and supremacy above the conventional drugs which side effects may aggravate existing symptomatic manifestations of pregnancy.

Alternative medicine which has a long history has been relegated to the background by the evolution of modern medicine. However, alternative medical therapy has been growing in popularity and getting increasing attention and interest ${ }^{[4,5]}$. Moreover, the use of herbal remedy as a form of alternate medical care among pregnant women has become a major concern in Nigerian communities due to its perceived safety among users and controversial assumption of toxicity, teratogenic potentials and associated feto-maternal complications among healthcare practitioners ${ }^{[5] .}$

Women are the largest consumers of healthcare, and this extends to their utilization of complementary and alternative medicine ${ }^{[6]}$. However, it is widely known that any kind of medicine used during pregnancy might have a harmful effect on both the mother and the fetus. The risk of damage done to the fetus is greatest in the first few weeks of pregnancy when major organs are developing ${ }^{[7]}$. Therefore, the use of herbs during pregnancy should be a subject of concern. For example, Born and Barron ${ }^{[8]}$ posited that many common plants have parts that contain natural toxins that could be dangerous if consumed.

Researchers have attempted to uncover the reasons why women turn to alternative medicine in general and to botanical medicine in particular ${ }^{[6]}$. According to Low Dog, the desire to have personal control over ones health has been cited as the strongest motive for women to use herbal remedies. Second was dissatisfaction with conventional treatment and its disregard for a holistic approach as well as concerns about the side effects of medications. These concerns may explain, in part, the fact that many women use herbal remedies during pregnancy ${ }^{[6]}$.

Two of the most common minor disorders during pregnancy are nausea and vomiting and both affect large proportion of women in early pregnancy. Yet, because it is a physiological symptom it is often dismissed by health professionals, leaving women to find their own coping mechanisms ${ }^{[9]}$. This has led many women to try a range of natural remedies, although the evidence of efficacy is variable. Furthermore, while women realize the possible risks of taking medication during pregnancy, they may not see herbal remedies in the same way.

In a setting like Nigeria where there is strong perception and widespread utilization of herbal preparations, it becomes imperative to investigate its use in pregnancy due to the effects it could have on the unborn child and the mother. Moreover, the need for nurses to have a reliable empirical data on the perception and utilization of herbal remedy in pregnancy is becoming extremely important for effective educational interventions. This will promote safe motherhood and reduce maternal and infant mortality resulting from misuse of herbs. Even though studies conducted across the six geo-political zones revealed strong perception of herbal remedy and high consumption rate among the Nigerian populace ${ }^{[5,10]}$, few research evidences exist on its use during pregnancy.

Considering the numerous symptoms associated with pregnancy due to physiological changes, there is higher probability of increased herbal consumption during pregnancy especially in rural communities. Moreover, research findings have consistently showed that herbal remedy is perceived to be safe due to its natural source ${ }^{[11]}$. It was also reported to be cheap, readily available and easily accessible with little self-control over the frequency and quantity taken at will. Due to these reasons, pregnant women may tend to use it more to relieve minor disorders during pregnancy. However, herbal remedy may contain substances that may be harmful to the fetus or the baby. Remedies have also been described to have the possibility of interacting with prescribed drugs and anaesthetic agents ${ }^{[12-15]}$ or cause fetal malformations ${ }^{[16,17]}$. In fact some authorities have cautioned against the use of almost all herbal remedies during pregnancy ${ }^{[18]}$. Despite this available information, pregnant women still use herbal remedies.

Since nurses and midwives are saddled with the responsibility of health promotion, prevention of complications and conservation of life through effective counseling and health education, the increasing demand for statistical data on the 
perception and pattern of use of herbal remedies during pregnancy in our immediate local communities will help to know the extent of their use and alternative measures to promote safety among the users.

The study provides a knowledge base for intervention programs to address issues relating to the use of herbal remedy among women during pregnancy. The study is aimed at (a) assessing women's perception of safety and efficacy of herbal drugs during pregnancy (b) examine the prevalence of utilization of herbal drugs by women during pregnancy (c) determine the common herbal remedies used by women in pregnancy and examine the factors that influence the utilization of herbal drugs during pregnancy.

\section{Conceptual perspective}

The revised health belief model by Champion ${ }^{[19]}$ provides the theoretical framework for this study. The Health Belief Model (HBM) is based on the understanding that a person will take a health related action (e.g. use of herbal remedies) if that person:

- feels that a negative health condition (e.g. losing pregnancy or illness ) can be prevented;

- has a positive expectation that by taking a recommended action, she will avoid a negative health condition (i.e. taking of herbal remedy will be effective at averting any health problems to self or baby); and

- believes that she can successfully take a recommended health action (i.e., she knows the herbal remedy to use and how to use it at averting any health problems early).

The basic tenet of the health belief model is that people will engage in health promoting behaviour when they perceive susceptibility to getting a particular disease condition, perceive that the condition is serious, perceive benefits from participating in behavior that can avert the disease conditions and perceive a lesser barrier in engaging in such a preventive behavior.

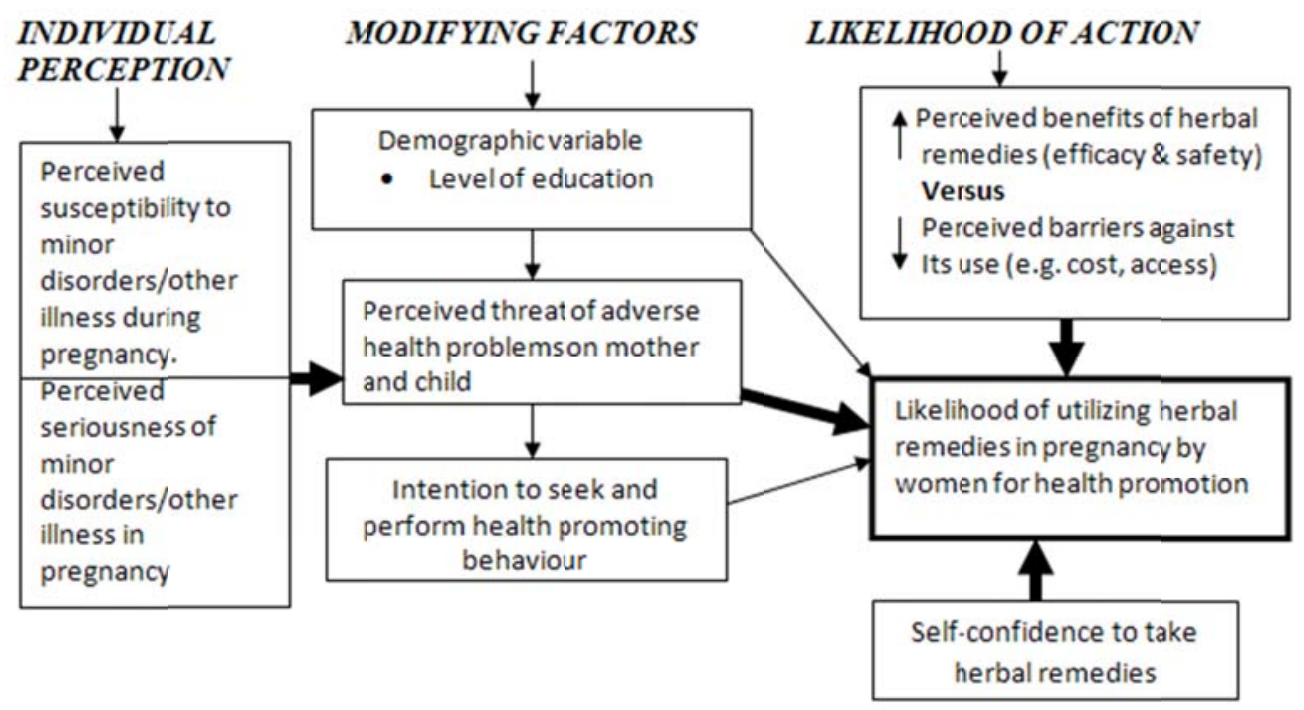

Figure 1. Model of utilization of herbal remedies among women

Source: Adapted from: Glanz, Rimer and Lewis ${ }^{[25]}$

The health belief model lays emphasis on perceived benefits which is conceptualized as the extent to which a person perceives greater benefits from engaging in a behavior over the barriers associated with such behavior. Health belief model 
posits that when people perceive greater benefits from engaging in behavior, there is higher likelihood that the people will engage in such behavior. For example, the women's perception of the benefits of using herbal remedies to promote health in pregnancy will influence the utilization of the same. In this study, the women perceived greater benefits of using herbal remedies when compared to the barriers. Table 5 shows the factors influencing utilization of herbal remedies among the women. From the table it can be deduced that the proportion of women who did not agreed with the ease of accessing herbal remedies, its low cost, the natural taste, its efficacy over orthodox medicine and better outcome with its use was low when compared with those that agreed with these factors.

Several studies have documented perceived benefits as a major HBM variable that influence people's participation in health promoting action ${ }^{[19-21]}$. In the HBM , the likelihood of people participating in health promoting behavior could also be influenced by individual socio-demographic variables such as sex, marital status, religious belief, and educational status. Out of these characteristics, educational status have been consistently linked to people's participation in health promoting action ${ }^{[22-24]}$. Figure 1 shows the interelationship of the concepts of the HBM as it is related to the study.

\section{Methodology}

Study Design: The study adopted descriptive cross-sectional design to explore women's perception of safety and utilization of herbal remedy during pregnancy.

Study Setting: The study took place in seven rural communities of Ife North Local Government Area of Osun State in Southwestern Nigeria. The local government has an area of $984 \mathrm{~km}^{2}$ with a population of 153,694 (of which 75,519 were female) according to the 2006 census. The major occupation of the people is farming and products are traded with neighboring communities.

Sampling Procedures: Three streets were selected from each of the seven communities by simple balloting. In each street, the houses were enumerated and systematic sampling used to select household that participated in the study. Convenience sampling was then used to select women that participated in the study from the selected households.

Sample Size Determination: The sample size was determined using a standard formula for a cross sectional study ${ }^{[26]}$. The formula is given as $n=z^{2} p q / d^{2}$ where $n=$ desired sample size (when population is greater than 10,000$), z=$ the standard normal deviate, usually set at 1.96 which corresponds to the 95 percent confidence interval, $\mathrm{p}=$ proportion in the target population estimated to have a particular characteristic, $\mathrm{q}=1.0-\mathrm{p}$, and $\mathrm{d}=$ degree of accuracy desired, usually set at 0.05 . The study utilized the prevalence of a previous study conducted among this population where $30 \%$ of women use herbal remedy ${ }^{[27]}$. A total sample of 322 was obtained. Three hundred and twenty (320) women were met at the selected household out of which $93.75(\mathrm{n}=300)$ gave consent to participate. Two of the women were not available for interview during the period of the survey despite the fact that the researchers visited on three occasions owing to their busy farm work while $6.25 \%(n=20)$ declined to take part in the survey for personal reasons. Those who participated in the study were women who were pregnant during the data collection, women whose baby were less than one year (nursing mothers) and older women in the selected households who provided support and care for both the pregnant women and the nursing mothers.

Data collection Method: Data was collected from women using a 24-item semi-structured questionnaires consisting of five sections transcribed to local language. The five-sectioned questionnaire was used to collect data on the sociodemographic characteristics of the women, the prevalence of utilization of herbal remedies by the women during pregnancy, common herbal remedies used by women in pregnancy, the women's perception of safety and efficacy of herbal drugs during pregnancy, and factors that influence their utilization of herbal drugs during pregnancy. The validity of the instrument was ensured through face and content validity by giving the instrument to experts in nursing, community health and researchers in alternative therapies. The reliability of the instrument was determined by test-retest method with 
alpha correlation of 0.89. Data was collected from respondents through research assistants who were trained to administer the questionnaire in the local language for a period of three weeks.

Table 1. Socio-demographic characteristics of respondents

\begin{tabular}{|c|c|c|}
\hline Characteristics & Frequency $(n=300)$ & Percentage (\%) \\
\hline Age at Last Birthday (yrs) & Mean Age $=32.80 \mathrm{SD}= \pm 10.84$ & \\
\hline $16-30$ & 146 & 48.7 \\
\hline $31-45$ & 114 & 38.0 \\
\hline $46-60$ & 38 & 12.7 \\
\hline $61-75$ & 2 & 0.7 \\
\hline \multicolumn{3}{|l|}{ Level of Education } \\
\hline No formal Education & 64 & 21.4 \\
\hline Primary school & 70 & 33.3 \\
\hline Secondary school & 105 & 35.3 \\
\hline Tertiary Education & 60 & 20.0 \\
\hline \multicolumn{3}{|l|}{ Ethnicity } \\
\hline Igbo & 58 & 19.3 \\
\hline Yoruba & 226 & 75.3 \\
\hline Hausa & 16 & 5.3 \\
\hline \multicolumn{3}{|l|}{ Religion } \\
\hline Christianity & 158 & 52.7 \\
\hline Islam & 132 & 44.0 \\
\hline Traditional & 10 & 3.3 \\
\hline \multicolumn{3}{|l|}{ Marital Status } \\
\hline Single & 64 & 21.3 \\
\hline Married & 206 & 68.7 \\
\hline Divorced & 2 & 0.7 \\
\hline Widow & 28 & 9.3 \\
\hline \multicolumn{3}{|l|}{ Number of Children } \\
\hline 0 & 46 & 15.3 \\
\hline 1 & 40 & 13.3 \\
\hline 2 & 78 & 26.0 \\
\hline 3 & 56 & 18.7 \\
\hline 4 & 48 & 16.0 \\
\hline 5-Above & 32 & 10.7 \\
\hline \multicolumn{3}{|l|}{ Occupation } \\
\hline Farmer & 20 & 6.7 \\
\hline House wife & 104 & 34.7 \\
\hline Petty trader & 120 & 40.0 \\
\hline Civil servant & 56 & 18.7 \\
\hline
\end{tabular}

Ethical Consideration: Permission was obtained from the medical officer of health from the local government area and a written consent in local language was also obtained from the respondents before the conduct of the study. Confidentiality 
of the respondents was maintained at all times by ensuring that participants are not linked to the questionnaires. Participation was voluntary, and respondents were informed of their right to withdraw at any time from the study if they so desired without any penalty.

Data Analysis: Data generated from the study was analyzed using Statistical Package for Social Sciences ${ }^{[28]}$ Version 17. Variables were examined for normality before further analyses were conducted. Descriptive statistics were used to describe the demographic characteristics of the sample and major study variables. Associations between variables were examined using Chi-square.

\section{Results}

A total of 300 respondents participated in the study. The mean age was 33 years \pm 10.84 with minimum age of 17 years and maximum age 68. The modal age group was 16-30 years and majority of the respondents belonged to the Yoruba ethnic group in Nigeria (see Table 1).

such as fever, abdominal pain, loss of appetite, cold and catarrh. Other herbal remedies utilized by women and the proportion of women that used it are aqueous ugwu $(26.7 \%$; $=80)$, aqueous bitter leaf $(22.7 \% ; n=68)$, ginger $(14 \% ; n=42)$ and few women $(4.7 \% ; n=14)$ reported to have used cannabis during pregnancy. The detail of the purposes of using the herbal remedies is as stated in Table 4.

\subsection{Respondents' perception of safety of herbal remedy}

Table 2 shows respondents' perception of the safety of herbal remedy. Perception was measured using 8 -item questions on a Likert scale and it was explained in two ways. It was positive if the women believed in the efficacy and safety of herbal remedies and negative when they disagreed. The study showed that majority of the women had positive perception about safety of herbal remedies during pregnancy. Over sixty percent of respondents perceived herbal remedies to be safe $(66.0 \% ; n=198)$ and efficient $(62.7 \% ; n=188)$ for managing common ailments during pregnancy. The findings from the study also showed that many of the respondents $(62.7 \% ; n=188)$ perceived herbal remedies to be effective in promoting health during pregnancy while the majority $(72.7 \% ; \mathrm{n}=218)$ were satisfied with the outcomes of using herbal remedy. It is also important to note that close to fifty percent $(45.3 \%, \mathrm{n}=136)$ recommended that herbal remedy should be used by all pregnant women.

Table 2. Perception of safety and efficacy of herbal drugs during pregnancy

\begin{tabular}{llll}
\hline Perception & Positive(\%) & Neutral(\%) & Negative(\%) \\
\hline $\begin{array}{l}\text { Herbal remedies are safer than pharmaceutical drugs during pregnancy. } \\
\text { Herbal remedies are very efficient for managing health problems during }\end{array}$ & $198(66.0)$ & $40(13.3)$ & $62(20.7)$ \\
$\begin{array}{l}\text { pregnancy. } \\
\text { Herbal remedies may cause problems or complications in pregnancy. }\end{array}$ & $88(29.3)$ & $142(47.3)$ & $70(23.3)$ \\
$\begin{array}{l}\text { Herbal remedies can help promote health during pregnancy. } \\
\text { Herbal remedies should be used by all women in pregnancy. }\end{array}$ & $188(62.7)$ & $54(18.0)$ & $58(19.3)$ \\
$\begin{array}{l}\text { I am satisfied with the effect and outcomes of using herbal medicines } \\
\text { during pregnancy. }\end{array}$ & $218(72.7)$ & $38(12.7)$ & $44(14.3)$ \\
\hline
\end{tabular}

\subsection{Utilization of herbal remedy and common remedy mostly used by respondents}

Table 3 presents the utilization of herbal remedies by respondents. The study showed that majority of the respondents $(70 \%, \mathrm{n}=210)$ had used herbal remedies in the previous pregnancies while $30.0 \%(\mathrm{n}=90)$ did not use herbal remedy. Over 
one third $(39.3 \%, \mathrm{n}=118)$ of the pregnant women stated that they had used herbal remedies during the current pregnancy while $38.7 \%(n=116)$ were not currently pregnant. Two-third $(70 \%, n=210)$ of the respondents would still want to use herbal remedy for subsequent pregnancies while $25.3 \%(n=76)$ said they won't use it and $(4.7 \%, n=14)$ were not sure if they will use it. One-third of the respondents $(48.0 \%$; $n=144)$ used herbal remedies in pregnancy to protect the baby against evil forces, twelve percent $(12 \% ; n=36)$ used it to augment labour while $4.0 \%(n=18)$ used it to induce abortion.

Table 3. Utilization of herbal drugs by women during pregnancy

\begin{tabular}{|c|c|c|}
\hline Utilization & $\begin{array}{l}\text { Frequency } \\
\mathrm{n}=\mathbf{3 0 0}\end{array}$ & $\begin{array}{l}\text { Percentage } \\
(\%)\end{array}$ \\
\hline \multicolumn{3}{|l|}{ Use herbal during previous pregnancy } \\
\hline Yes & 210 & 70.0 \\
\hline No & 90 & 30.0 \\
\hline \multicolumn{3}{|c|}{ Use herbal remedies in the current pregnancy } \\
\hline Yes & 118 & 39.3 \\
\hline No & 66 & 22.0 \\
\hline Not pregnant & 116 & 38.7 \\
\hline \multicolumn{3}{|c|}{ Will use herbal remedy for subsequent pregnancies } \\
\hline Yes & 210 & 70.0 \\
\hline No & 76 & 25.3 \\
\hline Don’t know & 14 & 4.7 \\
\hline \multicolumn{3}{|c|}{ Reasons for using herbal remedies in pregnancy } \\
\hline To induce labour & 18 & 6.0 \\
\hline To augment labour & 36 & 12.0 \\
\hline To protect the baby against evil & 144 & 48.0 \\
\hline To induce abortion & 12 & 4.0 \\
\hline Not using herbal remedy & 90 & 30.0 \\
\hline \multicolumn{3}{|c|}{ At what stage of pregnancy did you use herbal remedy } \\
\hline $1^{\text {st }}-3^{\text {rd }}$ Month & 51 & 17.0 \\
\hline $4^{\text {th }}-6^{\text {th }}$ Month & 6 & 2.0 \\
\hline $7^{\text {th }}-9^{\text {th }}$ Month & 24 & 8.0 \\
\hline During delivery & 14 & 4.7 \\
\hline Throughout the period of pregnancy & 115 & 38.3 \\
\hline Not using herbal remedy & 90 & 30.0 \\
\hline \multicolumn{3}{|c|}{$\begin{array}{l}\text { Through which route did you use herbal medicine during } \\
\text { pregnancy }\end{array}$} \\
\hline Through the mouth & 152 & 50.7 \\
\hline Through vaginal & 30 & 10.0 \\
\hline Through the skin & 20 & 6.7 \\
\hline Through mouth and skin & 8 & 2.7 \\
\hline Not applicable & 90 & 30.0 \\
\hline
\end{tabular}


A little above one third $(38.3 \% ; \mathrm{n}=115)$ of the respondents stated that they used herbal remedies throughout the period of pregnancy while $17.0 \%(n=51)$ used it in the first three months of pregnancy. Majority $(50.7 \% ; n=152)$ of the respondents who used herbal remedies during pregnancy took it orally while $2.7 \%(\mathrm{n}=8)$ used it orally and topically.

Findings also revealed that majority $(62.7 \% ; \mathrm{n}=188)$ of the respondents used concoction (agbo) as their major herbal remedy. Other herbal remedies used by the women include the local "agbo jedi" used by the women to manage constipation and low back pain. The "scent leaf" was used by $26 \%(\mathrm{n}=78)$ of the women to manage a range of problems

Table 4. Common herbal drugs used by women in pregnancy

\begin{tabular}{|c|c|c|c|}
\hline Common herbal drugs used & Yes (\%) & No (\%) & $\begin{array}{l}\text { Purposes of using herbal remedies } \\
\text { by women }\end{array}$ \\
\hline $\begin{array}{l}\text { Local concoction: Mixture of different herbs boiled } \\
\text { for drinking or bathing (locally called "agbo"). }\end{array}$ & $188(62.7)$ & $112(37.3)$ & $\begin{array}{l}\text { Protection of baby against evil forces } \\
\& \text { to make baby strong }\end{array}$ \\
\hline A brand of local concoction known as "Agbo jedi". & $80(26.7)$ & $220(73.3)$ & $\begin{array}{l}\text { To alleviate constipation \& back pain } \\
\text { symptoms }\end{array}$ \\
\hline $\begin{array}{l}\text { The Scent leaves: Locally called "Efirin" The leaf is } \\
\text { squeezed with salt and sieve to extract the water for } \\
\text { drinking. }\end{array}$ & $78(26.0)$ & $222(74.0)$ & $\begin{array}{l}\text { Abdominal pain, to treat loss of } \\
\text { appetites, fever, cold and catarrh }\end{array}$ \\
\hline $\begin{array}{l}\text { Ugwu vegetable: The leave is squeeze in water and mixed } \\
\text { with milk. }\end{array}$ & $68(22.7)$ & $232(77.3)$ & Nutritional supplements in pregnancy \\
\hline $\begin{array}{l}\text { Bitter leaf water: locally known as "Ewuro". The } \\
\text { leave is squeezed and sieve and the water extracted } \\
\text { for drinking or the leaf is used for soup preparation. }\end{array}$ & $52(17.3)$ & $248(82.7)$ & $\begin{array}{l}\text { Antiemetic, fever, relief constipation, } \\
\text { loss of appetite }\end{array}$ \\
\hline $\begin{array}{l}\text { Ginger: the ginger is either eaten raw or ground and } \\
\text { mixed with a local palm wine or soup. }\end{array}$ & $42(14.0)$ & $258(86.0)$ & Antiemetic \\
\hline $\begin{array}{l}\text { Cannabis: It is often prepared for consumption using } \\
\text { the local palm wine. }\end{array}$ & $14(4.7)$ & $286(95.3)$ & Pain Relieve \\
\hline
\end{tabular}

Table 5. Factors influencing the utilization of herbal drugs during pregnancy

\begin{tabular}{lllc}
\hline Factors & Yes (\%) & Don't Know (\%) & No (\%) \\
\hline Easy access to herbal remedy & $212(70.7)$ & $72(24.0)$ & $16(5.3)$ \\
Low cost of herbal remedy & $202(67.3)$ & $80(26.7)$ & $18(6.0)$ \\
Natural taste of herbal drug & $202(67.3)$ & $90(30.0)$ & $8(2.7)$ \\
Better and faster result compare with orthodox medicine & $198(66.0)$ & $90(30.0)$ & $12(4.0)$ \\
Enhance good delivery outcome & $174(58.0)$ & $82(27.3)$ & $44(14.7)$ \\
Parents and relatives advice & $154(51.3)$ & $98(32.7)$ & $48(16.0)$ \\
Dissatisfaction with attitude of health care workers & $88(29.3)$ & $132(44.0)$ & $80(26.7)$ \\
Lack of privacy at the hospital & $74(24.7)$ & $140(46.7)$ & $86(28.7)$ \\
Peer influence (social pressure) & $60(20.0)$ & $152(50.7)$ & $88(29.3)$ \\
Distance of public health facility & $52(17.3)$ & $110(36.7)$ & $138(46.0)$ \\
\hline
\end{tabular}

\subsection{Factors influencing utilization of herbal drugs during pregnancy}

Table 5 shows that very few respondents $(17.3 \% ; n=52)$ agreed that the distance of public health facility influenced their utilization of herbal remedies. Over half $(58.0 \% ; n=178)$ of the respondents said they used herbal remedy because they 
desired a favorable pregnancy outcome. Half of the respondents $(51.3 \% ; n=154)$ stated that parental or relative advise was a major factor that influenced utilization of herbal remedy by them. Few respondents $(20 \%$; $=60)$ agreed that social pressure was a factor in the use of herbal remedies during pregnancy while $29.3 \%(n=88)$ stated that attitude of hospital staff had also been a factor. Main factors identified were easy accessibility to it $(70.7 \% ; n=212)$, its low cost $(67.3 \%$; $\mathrm{n}=202)$, the natural taste of herbal remedies $(67.3 \% ; \mathrm{n}=202)$ and women's perception of the efficiency of herbal drugs $(66.0 \% ; \mathrm{n}=198)$ in this order.

A significant association was found between educational status of the women and utilization of herbal remedy $\left(\chi^{2}=93.37\right.$, $\mathrm{df}=3, p=0.000$ ). Women of low educational status were found using herbal remedies more compared with the highly educated ones. A significant association was also found between the women's perception of safety and efficacy of herbal remedies and their use of herbal remedy $\left(\chi^{2}=93.48, \mathrm{df}=1 p=0.000\right)$. It means that women with positive perception in this study were found to use herbal remedies more than those who have negative perception about its use.

\section{Discussion}

This study was conducted in Ife-North Local Government Area of Osun-State in Nigeria. A total of 300 respondents participated in the study with the mean age of 33 years $(+/-10.84)$.

The perception of the women about the safety of herbal remedies in this study corroborated the findings of Hollyer, Boon, Georgousis, Smith \& Elinarson ${ }^{[29]}$, and Lapi, Vannaco \& Moschini ${ }^{[30]}$ that women choose to use herbal remedies because they consider it safer than pharmaceutical drugs and also a naturally-derived product that is always safe. The belief of majority of the respondents on efficacy of herbal remedy in managing problems during pregnancy was similar to those reported by Fakeye, Adisa \& Ismail ${ }^{[27]}$ in a study where more than two-thirds of respondents who had used herbal remedies at one time or the other during pregnancy have confidence in the efficacy and safety of herbal remedies.

The number of women in this study who were not aware of the complications of herbal remedy and those who believed that it had better effect than orthodox medicine as well as their assertion in recommending it for other women was high and thus, it was in contrast to Mbwanji ${ }^{[31]}$ findings who discovered in his work that most of the respondents are aware of the bad effects of herbal remedies in pregnancy and only a few will recommend it to other women. Also the high usage of herbs among rural women in this study contradicted the findings of Louik, Gardiner \& Kelley, et al. ${ }^{[32]}$ who reported low usage (5.8\%) among their respondents but at par with the findings of Bamidele, Adebimpe \& Oladele ${ }^{[5]}$ who reported similar findings among urban respondents in Nigeria. The preference for herbal remedies by pregnant women in this study over orthodox medicine could be linked with the submission of Elujoba, Odeleye and Ogunyemi ${ }^{[10]}$ that alternative medicine is intrinsically interwoven with the culture of the people - a socioeconomic and sociocultural heritage.

Usage of herbal remedies among respondents and intentions to use it in the future pregnancy was very high and this was consistent with the findings of Mbwanji ${ }^{[31]}$ who found that forty six percent (46\%) of those who used herbal medicine in their immediate pregnancy will still want to use it in their future pregnancy. Findings of this study also revealed that majority of the respondents have used herbal remedy to manage one or more illnesses related to pregnancy and this confirmed the work of Westfall ${ }^{[33]}$ who reported that women utilize many coping strategies, including self-treatment with herbal medicine and other alternative therapies during pregnancy. Nordeng \& Havnen ${ }^{[1]}$ and Maats ${ }^{[34]}$ also reported in their work that herbal medicines may be used during pregnancy to treat pregnancy symptoms like nausea and vomiting. They may also be used to prepare for labor or for other unrelated health issues such as colds and respiratory illnesses or skin problems.

The assertion of some women on the use of herbal remedy to induce labour was in conjuction with the research conducted by Varga \& Veale ${ }^{[3]}$ and Goncalves ${ }^{[2]}$ who confirmed that in pregnancy herbs are normally used orally on a regular basis 
as a tonic to clean the womb and attain an easy and quick delivery, and in order to protect the child from evil and have a heahlthy child.

The agbo (concoction) which was the mostly used herbal remedies by pregnant women in this study was consistent with the findings of Fakeye, Adisa \& Ismail ${ }^{[27]}$ and Bamidele, Adebimpe \& Oladele ${ }^{[5]}$ in their studies conducted in Nigeria. They conclude that more than two-third of respondents had used herbal medicines in crude forms or as pharmaceutical prepackaged dosage forms, with a high percentage preferring self-prepared formulated concoction (agbo).

Other herbal remedies reportedly used by women in this study which some researchers have explored were bitter leaf and ginger and the effects they might have on pregnancy. The bitter leaf is a very important vegetable in Nigeria because of its diverse uses and it is found more in the gardens and homes than in markets generally. Meanwhile bitter leaf has been described to have strong oxytocic effects when introduced to a rat uterus. It is said to cause contraction that was sustained for up to 30 minutes ${ }^{[35]}$. Muanya therefore concluded that the aqueous herbal extract of bitter leaf can cause uterine contractions at low doses of less than $300 \mathrm{~g} / \mathrm{ml}$. Therefore, the use of bitter leaf should be discouraged most especially in the first trimester because it can increase uterine motility and subsequent abortion. Also Wen, Yang, \& Krewski, et al ${ }^{[36]}$ submitted that ginger is a common supplement used for treatment of morning sickness, but there are reports that usage may lead to abortion, mutation of the fetus or increased risk for bleeding. For example, Fischer-Rasmussen, Kjaer, Dahl, et al. ${ }^{[37]}$ submitted that ginger has been associated with mutagenesis in a culture of Escherichia coli (E.coli).

Even though cannabis is a controlled drug and its use is outlawed in Nigerian society, some women used cannabis in this study for pain relief, fever, catarrh and loss of appetites. The percentage of women who used cannabis in this study was very low compared with what was found among pregnant women in a study conducted in Britain, Columbia and Canada where higher percentages were reported ${ }^{[38]}$. However cannabis has been reported to be harmful in pregnancy. Cannabis, also known as marijuana, is a psychoactive drug with multiple effects including euphoria, mood changes and hallucinations. Its active ingredient is delta-9-THC (Tetrahydrocannabinoid), which acts on cannabinoid (CB1) receptor. THC is highly lipid-soluble which explains its high concentrations in brain and body tissues. Small to moderate doses are stored in tissues for long periods up to 2-3 weeks. Cannabis has enormous affinity for milk and produces a milk/plasma ratio of 8 , although the levels in milk are generally considered subclinical. THC crosses the placenta readily, and there is increasing evidence that it may increase rates of growth retardation, adverse neurodevelopment following prenatal exposure ${ }^{[39-41]}$. Based on these facts, its use should be discouraged in pregnancy.

The scent leaf (efirin) and ugwu vegetables reportedly being used by the women in this study are also used for vegetable soup and were considered to be edible and safe. Evidences are lacking on "efirin" (Ocimum grattissimum), ugwu (Telfara occidentalis) and local concoction (agbo) on their efficacy and safety in pregnancy. The local concoction (a mixture of herbs soaked in gin or water) was the most common local herbs used by the women and lack of evidences on its safety, efficacy and toxicity should be a source of concern for healthcare providers.

The pattern of usage demonstrated by the women in this study where most women used herbal remedies throughout the period of pregnancy supported the finding of Nordeng and Havnen ${ }^{[1]}$ which indicated an increasing pattern throughout the trimesters. This can be explained by the fact that most pregnant women were using it to protect their baby.

Foster, Dennings \& Wills, et al. ${ }^{[42]}$ submitted that the users of herbal supplements do not inform their primary care provider for the reasons that they will not approve it or that the alternative medicine is natural. Therefore, nurses and midwives need to be more meticulous during history taking to get such information from pregnant women to prevent the possibility of drug interactions, and consequently educate the women on the likely effects of taking such remedies.

The significant association between level of education and use of herbal remedy during pregnancy in this study was consistent with the work of Fakeye, Adisa \& Ismail ${ }^{[27]}$ who revealed in their study that educational qualification of respondents has statistical significant effects on respondents' views on the side effects of herbal medicines to the fetus and 
that women with low educational status use herbs more than those who are highly educated. Also, the significant association between perception of safety and use of herbal remedy during pregnancy as reflected in this study was in line with the findings of Azriani, Siti, Zulkifli, et al. ${ }^{[43]}$ who discovered that women with negative attitudes towards herbal medicines are less likely to use the herbal medicines. The same findings were reported in the United States by Klepser, Doucette \& Horton ${ }^{[44]}$. This was in consonance with the conceptual framework used for this study which was based on the assumption that people will undertake any health action when they have positive perception about the particular action.

\section{Nursing implication}

The findings of this study showed that the use of herbs was embraced by the women because of their perception of its safety and efficacy over the years and its use may not be easily stopped among the population studied. If the use of herbal remedy by pregnant women and the entire population of women are to be controlled during pregnancy, there is need for an evidence-based laboratory research that can explore the safety of some of these herbs. These evidences are essential in providing health information to women on the use of herbal remedies during pregnancy. Health professionals particularly midwives have a unique and distinct opportunity to fulfill this responsibility of educating pregnant women on potential benefits and risks of using herbal remedy during pregnancy most especially on the unborn child. The prerequisite of the fulfillment of these nursing responsibilities are knowledge and skills in obtaining information about the non-harmful herbal remedies that can be used during pregnancy; and also the harmful herbal remedies that must not be used during pregnancy. All these could only come from a rigorous collaborative research among healthcare team such as nurses/midwives, gynecologists, pharmacists, laboratory scientists and support from both national and international donor agencies.

\section{Recommendations}

The study emphasized the widespread use and strong perception of herbal medicines by pregnant women, highlighting an urgent need for midwives, community health nurses and health care practitioners to be aware of this practice and make efforts in obtaining information about the use of herbs by pregnant women. This will help to furnish women with information on the adverse effects they may have on the unborn fetus. Because many women in this study had confidence in the efficacy of herbal remedies and found them helpful as a cost effective and accessible alternative treatment, midwives, community health nurses and healthcare providers should therefore keep themselves abreast of evidences regarding potential benefits or harmful effects of herbal medicinal agents. From the findings of this study, the following recommendations are made:

- Midwives and healthcare professionals should routinely include herbal remedy category in the list of drug history when asking about the patient's drug use at booking. This will help to identify those who use herbal remedies and therefore assist them to take precautions relating to safety.

- Mothers, family members, friends and traditional birth attendants should be educated through community mobilisation and education programmes that alternative medicines particularly herbal remedies, may be harmful to the fetus and therefore should be taken with precaution or avoided during pregnancy if possible. Focussing on these groups of people is important because of the influence they could have on the decision of pregnant women to use herbal remedies.

- Considering the utilization of herbal remedy by the women in this study, there is need for rigorous laboratory exploration of common herbal remedies being used by women for their safety to both mothers and babies. Such evidences are needed for educating women on the safe use of herbal remedy. 
- Midwives should strongly caution high risk pregnant women e.g women with history of clotting disorders or bleeding, cardiac disease, pregnancy- induced hypertension, pre- eclamsia, diabetes mellitus, and HIV because of the interaction that herbal remedies could have with their regular drugs.

- Herbal remedies should also be avoided in multiple pregnancy, IVF pregnancy or other major obstetric complications.

\section{Limitations}

The scope of this work covered selected pregnant women, nursing mothers and women who care for pregnant women and nursing mothers in the rural communities of a Local Government Area in Nigeria. Considering the population that participated in the study, it may also be difficult to generalize the study to only pregnant women. This necessitates the need for exploring the use of herbal remedy among a larger sample size of pregnant women. One of the limitations of the study was that no record was taken of the outcome of previous pregnancies and the researchers could not follow up the current pregnancy to assess the likely effects of herbal drugs being used by the women. Further study in this area should be designed to follow up women on herbal remedies in order to generate further knowledge on the safety of these herbs. The study is also limited by its cross-sectional design, use of self report and convenience sampling.

\section{Conclusion}

The high usage of herbal remedies in this study and non- availability of empirical data on the safety and efficacy of these herbs necessitates a need for laboratory exploration of all the herbs to enhance provision of health information around their use. Also, there is need for nurses and midwives to be more skillful in health assessment to gather data that could endanger the lives of women and their unborn child and use such information to educate and manage women health-wise throughout the maternity cycle.

\section{Authors' contributions}

$\mathrm{AE}$ conceived the study. AE and $\mathrm{OO}$ designed the study, conducted the literature review, data collection and data analysis. Both authors contributed to data interpretation and manuscript writing with $\mathrm{AE}$ writing the majority of the paper. AE revised the paper after peer review.

\section{References}

[1] Nordeng H, Havnen G. Use of herbal drugs in pregnancy. Pharmacoepidemiology of Drug Safety. 2001; 13(6): 371-80. PMid:15170766 http://dx.doi.org/10.1002/pds.945

[2] Goncalves R. Assessment of Maternal and Fetal outcomes following Ingestion of Herbal Remedies. AMFIHR Study Protocol, Pretoria; 2001.

[3] Varga CA, Veale DJH. Isihlambezo: utilization patterns and potential health effects of pregnancy related traditional herbal medicine. Sociology and Science Medicine. 1997; 44(7): 911- 924. http://dx.doi.org/10.1016/S0277-9536(96)00104-9

[4] Stephen ML, Margaret LW, Robert MM. Complementary and Alternative Medical Practices: Training, Experience, and Attitudes of a Primary Care Medical School Faculty. The Journal of the American Board of Family Practice [Internet]. 2003 July 1[cited 2013 february 5 ]; 16 (4):318-326.

[5] Bamidele JO, Adebimpe WO, Oladele EA. Knowledge, attitude and use of Alternative medical Therapy among urban residents of Osun state southwestern Nigeria. Afr J tradit Complementary Altern Med. 2009; 6(3): 281-288.

[6] Low Dog T. The use of botanicals during pregnancy and lactation. Alternative Therapies in Health and Medicine. 2009 ; $15: 54-58$. PMid:19161049

[7] Shealy K. Complementary therapies in midwifery. In Fraser DM, Cooper MA, ed. Myles Textbooks for Midwives. Fourteenth Edition. London: Churchill Livingstone; 2003. 
[8] Born D, Barron ML. Herb use in pregnancy: what nurses should know. MCN Am J Matern Child Nurs. 2005; 30(3): 201-6. PMid:15867682 http://dx.doi.org/10.1097/00005721-200505000-00009

[9] Tiran D. The use of herbs by pregnant and childbearing women: a risk-benefit assessment. Complementary Therapies in Nursing and Midwifery. 2003; 9(4): 176 -181. http://dx.doi.org/10.1016/S1353-6117(03)00045-3

[10] Elujoba AA. Odeleye, OM. Ogunyemi, CM. Traditional medicine development for medical and dental primary health care delivery system in Africa. Afr. J. Trad. Comp. Alt. Med. 2005; 2(1): 46-61.

[11] Adams C, Connell S. Women's beliefs about "natural" hormones and natural hormone replacement therapy . Menopouse. 2001; 8 (6): 433-40. http://dx.doi.org/10.1097/00042192-200111000-00009

[12] Scott GN, Elmer GW. Update on natural product drug interactions. Am J Health System Pham. 2002; 59(4): 339-47. PMid:11885397

[13] Maliakal PP, Wanwimolruk S. Effect of herbal teas on hepatic drug metabolizing enzymes in rats. J Pharm Pharmacol. 2001; 53(10):1323-9. http://dx.doi.org/10.1211/0022357011777819

[14] Izzo AA, Ernst E. Interactions between herbal medicines and prescribed drugs: a systematic review. Drugs. 2001; 61(15):2163-75. http://dx.doi.org/10.2165/00003495-200161150-00002

[15] Ang-Lee MK, Moss J, Yuan CS. Herbal medicines and perioperative care. J Am Med Assoc. 2001; 286(2):208-16. http://dx.doi.org/10.1001/jama.286.2.208

[16] Simpson M, Parsons M, Greenwood J, Wade K. Raspberry leaf in pregnancy: its safety and efficacy in labour. J Midwifery \& Women's Health. 2001; 46(2): 51-9. http://dx.doi.org/10.1016/S1526-9523(01)00095-2

[17] Vaes LP, Chyka PA. Interactions of Warfarin with garlic, ginger, ginkgo or ginseng nature of the evidence. Ann Pharmacol. 2000; 34(12): 1478-82. http://dx.doi.org/10.1345/aph.10031

[18] Ernst E. The risk benefit profile of commonly used herbal therapies: Gingko, St. John's wort of inseng, Echinacea, sawpalmetto and kava. Ann int. Med. 2002; 136(1): 42-53. PMid:11777363 http://dx.doi.org/10.7326/0003-4819-136-1-200201010-00010

[19] Champion VL. Relationships of age to factors influencing breast self examination. Res. Nurs. Health. 1992; 10(6): $375-82$. http://dx.doi.org/10.1002/nur.4770100605

[20] Rakowski W, Rimer BK, Bryant SA. Integrating behaviour and intention regarding mammography by respondents in the 1990 National Health Interview survey of health promotion and disease prevention. Public Health Rep. 1993; 108(5): 605-24. PMid:8210259

[21] Thomas L, Fox S, Leake B, Roetzheim R. The effects of health beliefs on screening mammography utilization among a diverse sample of older women. Women's Health. 1996; 24(3): 77-91. http://dx.doi.org/10.1300/J013v24n03_05

[22] Maxwell AE, Bastani R, Warda US. Demographic predictors of cancer screening among Filipino and Korean immigrants in the United States. Amj Prev Med. 2000; 18 (1): 62-68. http://dx.doi.org/10.1016/S0749-3797(99)00110-5

[23] Maxwell CJ, Bancej CM, Snider J. Predictors of mammography use among Canadian women aged 50-69: Findings from the 1996/97 National Population Health Surveys. CMAJ. 2001; 164 (3): 329-34. PMid:11232132

[24] Olowokere AE, Onibokun AO, Irinoye O. Health beliefs of women and Breast cancer screening practices in selected rural communities of Oyo State. African Journal of Midwifery and Women's Health. 2012; 6(2): 12-20.

[25] Glanz K, Rimer, BK, Lewis, FM. Health Behaviour and Health Education Theory, Research and Practice. San Fransisco: Wiley \& Sons; 2002.

[26] Araoye MO. Research Methodology with statistics for health and social Sciences.Nathadex Publishers. 2004; $115-121$.

[27] Fakeye TO, Adisa R, Ismail ME. Attitude and use of herbal medicines among pregnant women in Nigeria. BMC Complementary and Alternative Medicine. 2009[cited 2013 February 10]; 9: 53. Available from

http://www.biomedcentral.com/content/pdf/1472-6882-9-53.pdf

[28] SPSS. SPSS statistics for windows, version 17.0. Chicago. SPSS Inc. 2008.

[29] Hollyer T, Boon H, Georgousis A, Smith M. Einarson A. The use of Complimentary and Alternative Medicine by women suffering from nausea and vomiting during pregnancy. BMC Complementary and Alternative Medicine [Internet]. 2002 May17 [cited 2013 February 5] ;2 (5):1-6. Available from http://www.biomedcentral.com/1472-6882/2/5.

[30] Lapi F, Vannaci A, Moschini M. Use, attitude and knowledge of complementary and Alternative drugs (CADs) among pregnant women: a preliminary survey in Joscany. Presented in Part at the Annual Meeting of the Society of Obstetric, Anesthesia and Perinatotology (SOAP), Montreal, Canada; 2008.

[31] Mbwanji JG. Prevalence of herbal medicine use and associated factors among pregnant women attending antenatal clinic at Mbeya Refferal Hospital. Muhimbili university institutional repository; 2012.

[32] Louik C, Gardner P, Kelley K, Mitchell A. Use of herbal treatment in pregnancy. Am J. Obstet Bynecol. 2010; 202(5): 439. e1-439.

[33] Westfall RE. Use of anti-emetic herbs in pregnancy; Women's choices, and the question of safety and efficacy. Complementary Therapies in Nursing \& Midwifery. 2004, 10(1):30-36. http://dx.doi.org/10.1016/S1353-6117(03)00057-X 
[34] Maats F. Crowther C. Patterns of vitamin, mineral and herbal supplement use prior to and during pregnancy. Austrialia New Zealand Journal of Obstetrics and Gynaecology. 2002; 42: 494-496. http://dx.doi.org/10.1111/j.0004-8666.2002.00494.x

[35] Muanya C. Bitter leaf-based drugs for diabetes, cancer pass clinical trials, get U.S. patients, G. Guardian Nigeria. 2008 [cited 2011 January 9]. Available from: http://onlinenigeria.com/templates/?a=13323

[36] Wen Y, Yang T, Krewski D, et al. Patterns of pregnancy exposure to prescriptions FDA C, D, and X in a Canadian population. J Perinatol. 2008; 28(5): 324-29. PMid:18288118 http://dx.doi.org/10.1038/jp.2008.6

[37] Fischer-Rasmussen W, Kjaer SK, Dahl C, Asping U. Ginger treatment of hyperemesis gravidarum. Eur. J Obstet Gynecol Reprod Biol. 1991; 38(1):19-24. http://dx.doi.org/10.1016/0028-2243(91)90202-V

[38] Westfall RE, Janssen PA, Lucas P, Capler R. Survey of medicinal cannabis use among childbearing women: patterns of its use in pregnancy and retroactive self-assessment of its efficacy against "morning sickness".Complementary Therapies in Clinical Practice. 2006; 12(1):27-33. PMid:16401527 http://dx.doi.org/10.1016/j.ctcp.2005.09.006

[39] HDay NL, Richardson GA, Geva D, Robles N. Alcohol, marijuana, and tobacco: effects of prenatal exposure on offspring growth and morphology at age six. Alcohol Clin Exp Res. 1994 Aug; 18(4):786-794. PMid:7526725 http://dx.doi.org/10.1111/j.1530-0277.1994.tb00041.x

[40] Fried PA. Prenatal exposure to marijuana and tobacco during infancy, early and middle childhood: effects and an attempt at synthesis. Arch Toxicol Suppl. 1995; 17: 233-60. PMid:7786162 http://dx.doi.org/10.1007/978-3-642-79451-3_21

[41] Hurd YL, Wang X, Anderson V, Beck O, Minkoff H, Dow-Edwards D. Marijuana impairs growth in mid-gestation fetuses. Neurotoxicol Teratol. 2005; 27(2): 221-229. PMid:15734273 http://dx.doi.org/10.1016/j.ntt.2004.11.002

[42] Foster D, Dennings A, Willls G, Bolger M, McCarthy E. Herbal medicine use during pregnancy in a group of Australian women. BMC Pregnancy Childbirth [Internet]. 2006 June 19 [cited 2013 February 9]. 6 (21). Available from http://www.ncbi.nlm.nlm.nih.gov/pmc/articles/pmc1544352/

[43] Azriani AR, Siti AS, Zulkifli A, Halim S, Wan N, Abdul MH. Women's attitude and socio-demographic Characteristics influencing usage of herbal medicines during pregnancy in Tumpat District, Kelantan. Department of Community Medicine Department of Pharmacology, School of Medical Sciences, Universiti Sains Malaysia, Kelantan, Malaysia; 2008.

[44] Klepser TB, Doucette, WR \& Horton MR, et al. Assessment of patients' perceptions and beliefs regarding herbal therapies. Pharmacotherapy. 2000; 20, 83-7. PMid:10641978 http://dx.doi.org/10.1592/phco.20.1.83.34658 